\title{
Association of increased levels of plasma tumor necrosis factor alpha with primary open-angle glaucoma
}

This article was published in the following Dove Press journal:

Clinical Ophthalmology

\author{
Altaf A Kondkar \\ Tahira Sultan \\ Faisal A Almobarak \\ Hatem Kalantan \\ Saleh A Al-Obeidan \\ Khaled K Abu-Amero \\ Glaucoma Research Chair, \\ Department of Ophthalmology, \\ College of Medicine, King Saud \\ University, Riyadh, Saudi Arabia
}

Correspondence: Khaled K Abu-Amero Glaucoma Research Chair, Department of Ophthalmology, College of Medicine, King Saud University, P.O. Box 245,

Riyadh II4II, Saudi Arabia

Tel +966 I I 2825290

Fax+966 I 14775742

Email abuamero@gmail.com
Purpose: Retinal ganglion cell (RGC) death is a key feature of glaucoma. Elevated levels of tumor necrosis factor alpha (TNF- $\alpha$ ), a pro-inflammatory cytokine, can induce RGC apoptosis and play a critical role in glaucomatous neurodegeneration. Based on the possible role of inflammation and oxidative stress in the pathogenesis of primary open-angle glaucoma (POAG), we investigated the association between plasma levels of TNF- $\alpha$ and POAG or its clinical indices in comparison to non-glaucomatous controls.

Patients and methods: In a case-control retrospective cohort of 51 POAG cases and 88 controls, plasma TNF- $\alpha$ levels were measured using an enzyme-linked immunosorbent assay (ELISA). The assay was performed in duplicates on an automated ELISA analyzer.

Results: Mean TNF- $\alpha$ level was significantly elevated in POAG cases $(1.88 \pm 2.17 \mathrm{pg} / \mathrm{mL})$ than the controls $(0.93 \pm 1.49 \mathrm{pg} / \mathrm{mL} ; p=0.003)$. The overall dose-response trend was significant $\left(\chi^{2}=6.12, \mathrm{df}=2 ; p=0.047\right)$. No statistical difference was seen in age, gender and systemic disease distribution. A modest negative and significant correlation was seen between TNF- $\alpha$ level and number of antiglaucoma medications, an important clinical index of POAG severity. Moreover, logistic regression analysis showed that the risk of POAG was most significantly affected by TNF- $\alpha$ level and not by age and sex.

Conclusion: High systemic level of an inflammatory cytokine, TNF- $\alpha$, is associated with POAG; however, its possible use as a biomarker for early glaucoma diagnosis and/or disease severity needs further investigation.

Keywords: apoptosis, biomarker, cytokines, ELISA, inflammation, neurodegeneration, oxidative stress

\section{Introduction}

Glaucoma is a group of optic neuropathies characterized by progressive damage to retinal ganglion cells (RGCs), resulting in characteristic cupping of the optic nerve head and loss of peripheral vision. ${ }^{1}$ Primary open-angle glaucoma (POAG) is the second most common form of glaucoma in Saudi Arabia, which is clinically characterized by an open and normal anterior iridocorneal chamber angle. ${ }^{2}$ Although POAG is clinically well defined, the underlying pathological mechanism(s) leading to the loss of RGCs is not yet completely understood. Aging, gender, African ancestry, family history, high intraocular pressure (IOP), central corneal thickness, myopia and genetic predisposition are some of the well-recognized risk factors associated with POAG pathogenesis. ${ }^{3}$ In addition, there is evidence of significant oxidative damage in human trabecular meshwork cells of patients with glaucoma, causing elevated IOP and visual field damage. ${ }^{4}$ Although IOP is considered a major risk factor for glaucoma, the role 
of other concomitant factors affecting the pathophysiology of glaucomatous RGC apoptosis, such as retinal ischemia, ${ }^{5}$ antioxidant status ${ }^{6}$ and several cytokines like interleukins, interferon-gamma and tumor necrosis factor alpha (TNF- $\alpha$ ), has also been extensively investigated. ${ }^{7,8}$

Cytokine release and oxidative stress can contribute to the pathogenesis of glaucomatous degeneration. ${ }^{9}$ TNF- $\alpha$ is a pro-inflammatory and neuroprotective cytokine that plays an important role in various immunological and physiological processes associated with retinal ischemia, neuronal damage and tissue regeneration. ${ }^{10}$ The diverse roles of TNF- $\alpha$ are mediated via two distinct receptors - a $55 \mathrm{kDa}$ receptor 1 (TNF-R1) and a $75 \mathrm{kDa}$ receptor 2 (TNF-R2) - and depend on which receptor is activated. ${ }^{11}$ Stimulation via TNF-R2 is neuroprotective and promotes tissue regeneration, whereas activation via TNF-R1 leads to recruitment of immune cells causing inflammation. Moreover, TNF-R1 can directly induce oxidative stress by the activation of reactive oxygen and nitrogen species-producing enzymes. ${ }^{12}$ Both, TNF- $\alpha$-induced oxidative stress and inflammation interact and cooperate to promote neurodegeneration, suggesting a causative role of TNF- $\alpha$ in neurodegenerative disorders, including glaucoma. ${ }^{10,12}$

Previous studies have demonstrated an increased concentration of cytokine TNF- $\alpha$ in glaucomatous aqueous humor $(\mathrm{AH})^{13,14}$ or serum cytokines ${ }^{15}$ in patients with POAG and have shown that TNF- $\alpha$ is capable of inducing RGC apoptosis, suggesting a critical role of TNF- $\alpha$ in glaucomatous degeneration. ${ }^{12,16}$ TNF- $\alpha$ is expressed in optic nerve and retina of human glaucomatous eyes which parallels with the progression of optic nerve damage. ${ }^{17}$ Moreover, we recently showed elevated levels of plasma TNF- $\alpha$ in a group of patients with pseudoexfoliation glaucoma. ${ }^{18}$

Since inflammation is an important aspect of various age-related disorders, including POAG, cytokine levels can serve as potential biomarkers in clinical practice. Based on the role of inflammation and oxidative stress in the pathogenesis of POAG, we investigated the relationship between plasma levels of TNF- $\alpha$ and POAG or its clinical indices as compared to non-glaucomatous controls.

\section{Patients and methods}

\section{Study population}

The study followed the Declaration of Helsinki guidelines for conducting research involving humans and was approved by the Institutional Review Board and Ethics Committee of College of Medicine, King Saud University (approval number 08-657). Written informed consent was obtained from all participants. A case-control retrospective cohort was selected to perform the investigation. Individuals of Saudi origin with clinical diagnosis of POAG and nonglaucomatous controls of the same ethnicity were recruited at King Abdulaziz University Hospital in Riyadh, Saudi Arabia. The inclusion and exclusion criteria have been described previously. ${ }^{6}$ In the POAG patients $(\mathrm{n}=51)$, the disc or retinal nerve fiber layer showed the following characteristics: thinning or notching of disc rim, progressive changes, nerve fiber layer defect; presence of characteristic abnormalities in visual field (eg, arcuate scotoma, nasal step, paracentral scotoma, generalized depression) in the absence of other causes or explanation and open anterior chamber angles bilaterally on gonioscopy. Cases with evidence of secondary glaucoma, for example, pigmentary dispersion syndrome, pseudoexfoliation, history of steroid use or ocular trauma were excluded. Individuals $(\mathrm{n}=88)$ with normal IOP, open angles on gonioscopy and healthy optic disc on examination served as controls. None of the participants included in this study were reported to have any infectious or immunomodulating diseases (rheumatoid arthritis, lupus, Crohn's disease). Subjects refusing to participate were also excluded.

\section{Sample collection and TNF- $\alpha$ estimation by enzyme-linked immunosorbent assay (ELISA)}

Plasma samples were obtained from ethylenediaminetetraacetic acid blood and stored at $-80^{\circ} \mathrm{C}$ until use. Plasma TNF- $\alpha$ level was measured using an ELISA (Catalog No STA00C, Quantikine ${ }^{\circledR}$ ELISA; R\&D Systems Inc., Minneapolis, MN, USA) in 51 POAG cases and 88 non-glaucomatous controls as described previously. ${ }^{18}$ The assay utilizes a monoclonal antibody specific for human TNF- $\alpha$ that is precoated onto a microplate and was performed in duplicate on a ChemWell-T bioanalyzer (Awareness Technology Inc., Palm City, FL, USA), as per the manufacturer's instructions (R\&D Systems Inc.). The steps were programmed using a ChemWell-T Assay Editor in the standard ELISA assay mode. The steps included addition of $50 \mu \mathrm{L}$ of assay diluent and $200 \mu \mathrm{L}$ of plasma sample/standard with mixing for $1 \mathrm{~min}$ and $2 \mathrm{~h}$ incubation at room temperature (RT). This was followed by washing ( $4 \times$ with a soak time of $30 \mathrm{~s}$ ), addition of TNF- $\alpha$ conjugate $(200 \mu \mathrm{L})$, mixing for $1 \mathrm{~min}$ and incubation for $2 \mathrm{~h}$ at RT. A $200 \mu \mathrm{L}$ of substrate, prepared immediately before use by mixing equal volumes of stabilized hydrogen peroxide and tetramethylbenzidine, was added after washing ( $4 \times$ with a soak time of $30 \mathrm{~s}$ ). The plate was incubated in dark at RT for $20 \mathrm{~min}$ with continuous mixing for $1 \mathrm{~min}$. The final reaction was terminated with $50 \mu \mathrm{L}$ of stop solution 
(2 $\mathrm{N}$ sulfuric acid), and absorbance was measured at 450 $\mathrm{nm}$ with wavelength correction set at $540 \mathrm{~nm}$. The TNF- $\alpha$ concentration was estimated from the calibrated standard curve and expressed in picograms per milliliter.

\section{Statistical analysis}

Data were presented as mean \pm SD for TNF- $\alpha$ level and other clinical variables. Analyses were performed using Student's $t$-test (two tailed), Pearson's chi-square test and nonparametric Mann-Whitney $U$-test to evaluate the differences between the two study groups. Correlation testing was done using Spearman's rho test. Logistic regression analysis was performed to estimate the impact and direction of the effect of other risk factors and mean TNF- $\alpha$ level in patients with POAG. A receiver operating characteristic (ROC) curve was generated, and the area under the curve (AUC) value was calculated using Mann-Whitney $U$-test. The confidence interval (CI) was set to $95 \%$, and $p<0.05$ was considered statistically significant. Statistical analysis was performed with SPSS, version 19.0 (IBM Corp., Armonk, NY, USA).

\section{Results}

Table 1 shows the demographic characteristics, status of systemic conditions and TNF- $\alpha$ level in the POAG cases and control groups included in this study. The two study groups were similar for age $(p=0.409)$, gender $(p=0.697)$ and distribution of other systemic conditions $(p>0.05)$. The mean TNF- $\alpha$ level was significantly higher in the POAG patients $(1.88 \pm 2.17 \mathrm{pg} / \mathrm{mL})$ than the control subjects $(0.93 \pm 1.49 \mathrm{pg} / \mathrm{mL} ; 95 \% \mathrm{CI}=0.33-1.56 ; p=0.003)$. The median values for TNF- $\alpha$ level among the cases and the control subjects were $0.90 \mathrm{pg} / \mathrm{mL}$ (range $=0-6.8$ ) and $0 \mathrm{pg} / \mathrm{mL}$ (range $=0-8$ ), respectively, and were also significantly different $(p=0.008)$ (Figure 1).

Table I Demographics, clinical characteristics and TNF- $\alpha$ level in POAG cases and controls

\begin{tabular}{llll}
\hline Variables & $\begin{array}{l}\text { POAG } \\
(\mathbf{n}=\mathbf{5 I})\end{array}$ & $\begin{array}{l}\text { Controls } \\
(\mathbf{n}=\mathbf{8 8})\end{array}$ & p-value \\
\hline Age, mean (SD) (years) & $59.0(\mathrm{I3.2})$ & $57 . \mathrm{I}(\mathrm{I} 2 . \mathrm{I})$ & $0.409^{\mathrm{a}}$ \\
Gender (M/F) & $29 / 22$ & $53 / 35$ & $0.697^{\mathrm{b}}$ \\
Diabetes mellitus, n (\%) & $22(43 . \mathrm{I})$ & $28(3 \mathrm{I} .8)$ & $0.287^{\mathrm{b}}$ \\
Hypertension, n (\%) & $20(39.2)$ & $28(3 \mathrm{I} .8)$ & $0.377^{\mathrm{b}}$ \\
Hypercholesterolemia, n (\%) & $2(3.9)$ & $3(3.4)$ & $0.75 \mathrm{I}^{\mathrm{b}}$ \\
Coronary artery disease, n (\%) & $\mathrm{I}(\mathrm{I} .9)$ & $2(3.4)$ & $0.628^{\mathrm{b}}$ \\
Smoking, n (\%) & $2(3.9)$ & $4(4.5)$ & $0.795^{\mathrm{b}}$ \\
TNF- $\alpha$, mean (SD) (Pg/mL) & $\mathrm{I} .88(2.17)$ & $0.93(\mathrm{I} .49)$ & $0.003^{\mathrm{a}}$ \\
\hline
\end{tabular}

Notes: andependent sample $t$-test. 'Pearson's chi-square test.

Abbreviations: F, female; M, male; POAG, primary open-angle glaucoma; TNF- $\alpha$, tumor necrosis factor alpha.

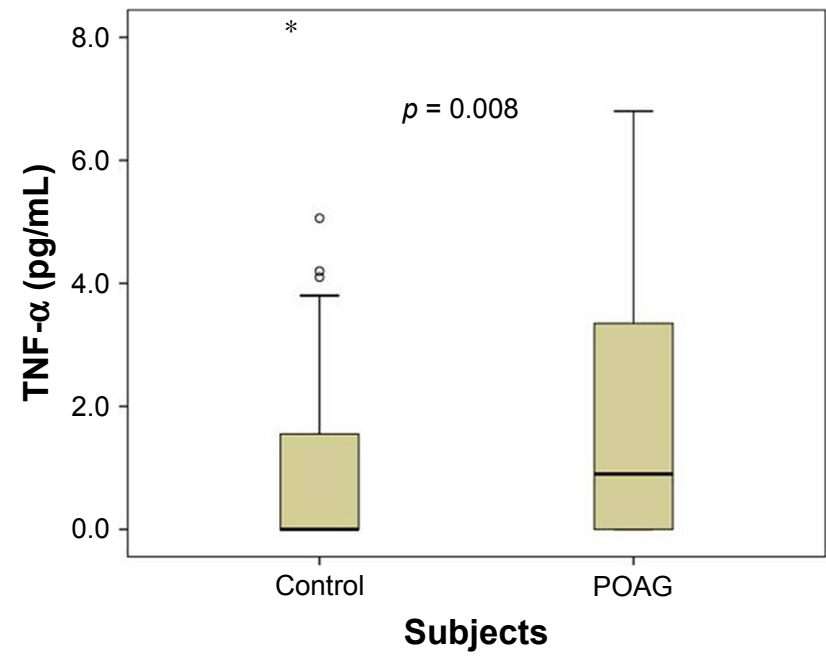

Figure I Box plot showing the distribution of TNF- $\alpha$ levels in the POAG cases and control group.

Abbreviations: POAG, primary open-angle glaucoma; TNF- $\alpha$, tumor necrosis factor alpha.

To assess any dose-response trend, the data was dichotomized (uncategorized) into quartiles, and two cutoff points were identified at $0.0 \mathrm{pg} / \mathrm{mL}$ (first quartile or the 25 th percentile) and $2.3 \mathrm{pg} / \mathrm{mL}$ (third quartile or the 75 th percentile). Subjects were then categorized into three groups by using these two cutoff points. The overall dose-response trend was statistically significant $\left(\chi^{2}=6.12, \mathrm{df}=2 ; p=0.047\right.$ ). Comparison between individuals where TNF- $\alpha$ was absent or its concentration was undetectable $(0 \mathrm{pg} / \mathrm{mL}$; first quartile $)$ and individuals in the medium category $(0.1-2.3 \mathrm{pg} / \mathrm{mL}$; interquartile) did not yield any significant association; however, individuals in the highest category $(>2.3 \mathrm{pg} / \mathrm{mL}$; third quartile) showed increased risk of the disease (odds ratio $=3.54$, 95\% CI $=1.51-8.27 ; p=0.0028$; Table 2).

A correlation testing between TNF- $\alpha$ levels and age and other clinical indices relevant to POAG, such as IOP, cupto-disc ratio and number of antiglaucoma medications, was performed using Spearman's correlation. A modest negative

Table 2 Quartile distribution of TNF- $\alpha$ level to assess the risk of POAG

\begin{tabular}{|c|c|c|c|c|c|}
\hline $\begin{array}{l}\text { TNF- } \alpha \\
\text { (pg/mL) by } \\
\text { quartiles }^{\mathrm{a}}\end{array}$ & $\begin{array}{l}\text { Cases } \\
(n=5 I), \\
n(\%)\end{array}$ & $\begin{array}{l}\text { Controls } \\
(n=88), \\
n(\%)\end{array}$ & $\begin{array}{l}\text { Odds } \\
\text { ratio }\end{array}$ & $\begin{array}{l}95 \% \\
\text { confidence } \\
\text { interval }\end{array}$ & $p$-value \\
\hline & $18(35.3)$ & 51 (57.9) & & - & - \\
\hline $0.1-2$. & $13(25.5)$ & $21(23.8)$ & 1.75 & $0.73-4.21$ & 0.206 \\
\hline$>2.3$ & $20(39.2)$ & $16(18.1)$ & 3.54 & $1.5 \mid-8.27$ & 0.0028 \\
\hline
\end{tabular}

Notes: aFirst quartile: $<25$ th percentile; interquartile: 25 th-75th percentile; third quartile: $>75$ th percentile. Overall dose-response trend was significant $\left(\chi^{2}=6.12\right.$, $\mathrm{df}=2 ; p=0.047)$.

Abbreviations: POAG, primary open-angle glaucoma; TNF- $\alpha$, tumor necrosis factor alpha. 
Table 3 Correlation between TNF- $\alpha$ level and other clinical variables

\begin{tabular}{lll}
\hline Variables & $\boldsymbol{R}$ & $\boldsymbol{p}$-value \\
\hline Age & 0.124 & 0.155 \\
Intraocular pressure & -0.197 & 0.179 \\
Cup-to-disc ratio & -0.031 & 0.836 \\
Number of antiglaucoma medications & -0.285 & 0.042 \\
\hline
\end{tabular}

Note: $R$, Spearman's correlation coefficient.

Abbreviation: TNF- $\alpha$, tumor necrosis factor alpha.

correlation was observed with the number of antiglaucoma medications ( $p=0.042)$, but there was no significant correlation with the age of onset, IOP and cup-to-disc ratio (Table 3). Logistic regression analysis showed that the risk of disease outcome (POAG) was most significantly affected by TNF- $\alpha$ level $(p=0.004)$ but not by age and sex (Table 4$)$.

Moreover, to determine whether the levels of plasma TNF- $\alpha$ can be used to discriminate between POAG cases and controls, we generated an ROC curve. Comparison of POAG patients with controls yielded an ROC curve area (AUC) of $0.625(95 \% \mathrm{CI}=0.526-0.724)$ that was statistically significant ( $p=0.014$ ) but exhibited a poor discriminatory power to distinguish between POAG cases and controls.

\section{Discussion}

Glaucoma is characterized by the progressive loss of RGCs resulting in gradual loss of vision and blindness. However, the underlying mechanism(s) promoting RGC damage is still unclear. Accumulating evidence suggests a key role for inflammatory cytokine in glaucomatous degeneration. ${ }^{9-11}$ Glaucomatous insults, such as axonal injury, elevated IOP, ischemia or obstruction by lamina cribrosa, trigger apoptosis and increased oxidative stress leading to the formation of reactive oxygen and nitrogen species at the localized tissues initiating cytokine secretion in various inflammatory cells. ${ }^{9,10}$ In this study, we demonstrate a clear association between increased levels of plasma TNF- $\alpha$ and POAG.

Since cytokines are important mediators of the inflammatory process, multiple studies have assessed the local and systemic profile of cytokine TNF- $\alpha$ levels in patients with

Table 4 Binary logistic regression analysis to determine the effect of age, sex and TNF- $\alpha$ level on disease outcome

\begin{tabular}{llll}
\hline Variables & Odds ratio & $\begin{array}{l}\mathbf{9 5 \%} \text { confidence } \\
\text { interval }\end{array}$ & p-value \\
\hline Age & 1.01 & $0.977-1.038$ & 0.645 \\
Sex & 0.997 & $0.467-2.126$ & 0.993 \\
TNF- $\alpha$ & 1.35 & $1.100-1.650$ & 0.004 \\
\hline
\end{tabular}

Note: aFemale as reference.

Abbreviation: TNF- $\alpha$, tumor necrosis factor alpha.
POAG using different approaches and variable end points. Sawada et al reported elevated levels of TNF- $\alpha$ in the AH of patients with pseudoexfoliation glaucoma and POAG. ${ }^{13}$ However, the increase in POAG cases was not significant. Similarly, Balaiya et al reported significant elevation of AH TNF- $\alpha$ in POAG. ${ }^{14}$ Using multiplex cytokine analysis, several other investigators reported there was no change in aqueous TNF- $\alpha$ in POAG ${ }^{19-24}$ compared to other cytokines. However, using multiplex approach, Tong et al reported significant elevation in vitreous TNF- $\alpha$ in POAG patients. ${ }^{25}$ Similar to our finding of increased plasma cytokine, TNF- $\alpha$, in $\mathrm{POAG}$ patients, Huang et al reported significant alterations of serum TH1 and TH2 cytokines in POAG as compared to non-glaucomatous controls, suggesting a plausibility of abnormal immune environments contributing to the glaucomatous neuropathy in POAG ${ }^{15}$ In addition, based on a similar mechanism of an activated immune response, we recently demonstrated an association between plasma TNF- $\alpha$ and pseudoexfoliation glaucoma. ${ }^{18}$

As compared to most studies reported in the literature (discussed above) that utilized AH to estimate TNF- $\alpha$ level in POAG, we estimated TNF- $\alpha$ level from plasma in a group of clinically well-defined POAG patients and compared it to non-glaucomatous controls devoid of any ophthalmic disorders. TNF- $\alpha$ levels are known to be affected by age, infection and other systemic conditions such as diabetes, hypertension and atherosclerosis. ${ }^{26}$ Therefore, care was taken to exclude individuals with infectious/autoimmune disease and select matching controls in terms of age, ethnicity, gender and systemic conditions. Both the mean and median TNF- $\alpha$ levels were significantly increased in our POAG cohort, and the effect was dose dependent. Besides, since the two study groups were similar for systemic diseases, the increase in TNF- $\alpha$ in the plasma could be more plausibly related to POAG condition rather than to any of the systemic disorders. Furthermore, TNF- $\alpha$ level exhibited a modest negative correlation with the number of antiglaucoma medications, a clinical index to assess severity of the disease, suggesting its utility as a marker of disease severity. In contrast, however, the AUC analysis indicated that TNF- $\alpha$ was a poor marker to discriminate between POAG cases and non-glaucomatous controls. Clearly, further investigations are needed to substantiate these findings in a much larger cohort. However, the elevated level of TNF- $\alpha$ in the plasma (in this study) and the AH (previous studies) is a clear indication of an activated immune response triggered by inflammation and its plausible association with glaucomatous degeneration, ${ }^{12}$ which is in accordance to our previous observation in pseudoexfoliation glaucoma. ${ }^{18}$ 
A number of previous studies have provided evidence for a role of TNF- $\alpha$ in glaucomatous degeneration. An increased expression of retinal TNF- $\alpha$ mRNA has been reported to be associated with RGC loss and optic aptropy. ${ }^{16}$ Similarly, administration of exogenous TNF- $\alpha$ has been demonstrated to promote RGC loss and optic nerve degeneration, whereas genetic or pharmacological depletion of TNF- $\alpha$ or its receptors has been shown to stimulate RGC survival. ${ }^{12}$ Although the specific reason and mechanism of the relationship between high levels of TNF- $\alpha$ (or cytokines in general) and glaucoma is still uncertain, in vitro experiments have demonstrated that TNF- $\alpha$ can induce RGC death through caspase- 3 and caspase- 8 activation and/or via the mitochondrial cell death pathway by inducing oxidative damage. ${ }^{12}$ The observation that the mean TNF- $\alpha$ level was elevated in POAG patients in comparison to age-, gender- and ethnicity-matched non-glaucomatous controls certainly suggests increased inflammation that may contribute to the creation of an oxidative stress status and, in a mechanism(s) described above, such a situation may contribute to glaucoma development and/or progression. Besides, an SNP (G-308A of rs 1800629) upstream of the promoter site of TNF- $\alpha$ has been reported to cause elevation of TNF- $\alpha$ and is positively associated with POAG in the Turkish, Egyptian and Iranian populations. ${ }^{27-29}$ Similarly, there is also some evidence for the role of mitochondrial abnormalities in patients with POAG from Saudi Arabia. ${ }^{30}$ A plausibility of similar mechanism(s) or as of yet unrecognized gene-gene or gene-environment interaction by elevated systemic levels of this marker contributing to glaucoma in our patients cannot be ruled out in this study.

There are certain limitations to this study. Primarily, we acknowledge the fact that the systemic increase in TNF- $\alpha$ level may not represent the exact intraocular microenvironment at the anterior segment structures, which are directly exposed to free radicals and are thus more pathophysiologically relevant in the development and progression of glaucoma through the oxidative stress or other mechanism(s). In the absence of any evidence of a direct correlation between cytokine alteration in the serum or plasma and cytokine levels in the eyes, this would require assessment of TNF- $\alpha$ level in AH samples. The study was limited to estimation of only a single cytokine. In addition, the sample size investigated was small, especially of POAG cases; thus, the statistical power of the study may be limited.

\section{Conclusion}

We found increased levels of plasma TNF- $\alpha$ in patients with POAG as compared to non-glaucomatous controls, indicating that high systemic levels of this inflammatory marker might be associated with POAG. However, further investigations in a large cohort and different ethnicities are needed to substantiate our findings.

\section{Acknowledgments}

The authors would like to thank the Deanship of Scientific Research and Glaucoma Research Chair of Department of Ophthalmology, College of Medicine, King Saud University, for their support and use of laboratory facilities. The funder had no role in the design of the study and collection, analysis and interpretation of data and in writing the manuscript. The article has not been presented in any previous conference or scientific meeting.

\section{Author contributions}

All authors contributed toward data analysis, drafting and revising the article and agreed to be accountable for all aspects of the work.

\section{Disclosure}

The authors have no conflict of interests in this work, and the study was not supported or funded by any drug company.

\section{References}

1. Kwon YH, Fingert JH, Kuehn MH, Alward WL. Primary open-angle glaucoma. N Engl J Med. 2009;360(11):1113-1124.

2. Al Obeidan SA, Dewedar A, Osman EA, Mousa A. The profile of glaucoma in a Tertiary Ophthalmic University Center in Riyadh, Saudi Arabia. Saudi J Ophthalmol. 2011;25(4):373-379.

3. Abu-Amero K, Kondkar AA, Chalam KV. An updated review on the genetics of primary open angle glaucoma. Int J Mol Sci. 2015;16(12): 28886-28911.

4. Izzotti A, Cartiglia C, De Flora S, Sacca S. Methodology for evaluating oxidative DNA damage and metabolic genotypes in human trabecular meshwork. Toxicol Mech Methods. 2003;13(3):161-168.

5. Butt Z, O’Brien C, McKillop G, Aspinall P, Allan P. Color Doppler imaging in untreated high- and normal-pressure open-angle glaucoma. Invest Ophthalmol Vis Sci. 1997;38(3):690-696.

6. Abu-Amero KK, Kondkar AA, Mousa A, Osman EA, Al-Obeidan SA. Decreased total antioxidants in patients with primary open angle glaucoma. Curr Eye Res. 2013;38(9):959-964.

7. Tezel G. Oxidative stress in glaucomatous neurodegeneration: mechanisms and consequences. Prog Retin Eye Res. 2006;25(5):490-513.

8. Munoz-Fernandez MA, Fresno M. The role of tumour necrosis factor, interleukin 6, interferon-gamma and inducible nitric oxide synthase in the development and pathology of the nervous system. Prog Neurobiol. 1998;56(3):307-340.

9. Nita M, Grzybowski A. The role of the reactive oxygen species and oxidative stress in the pathomechanism of the age-related ocular diseases and other pathologies of the anterior and posterior eye segments in adults. Oxid Med Cell Longev. 2016;2016:3164734.

10. Fischer R, Maier O. Interrelation of oxidative stress and inflammation in neurodegenerative disease: role of TNF. Oxid Med Cell Longev. 2015; 2015:610813.

11. Agarwal R, Agarwal P. Glaucomatous neurodegeneration: an eye on tumor necrosis factor-alpha. Indian J Ophthalmol. 2012;60(4):255-261. 
12. Tezel G. TNF-alpha signaling in glaucomatous neurodegeneration. Prog Brain Res. 2008;173:409-421.

13. Sawada H, Fukuchi T, Tanaka T, Abe H. Tumor necrosis factor-alpha concentrations in the aqueous humor of patients with glaucoma. Invest Ophthalmol Vis Sci. 2010;51(2):903-906.

14. Balaiya S, Edwards J, Tillis T, Khetpal V, Chalam KV. Tumor necrosis factor-alpha (TNF-alpha) levels in aqueous humor of primary open angle glaucoma. Clin Ophthalmol. 2011;5:553-556.

15. Huang P, Qi Y, Xu YS, et al. Serum cytokine alteration is associated with optic neuropathy in human primary open angle glaucoma. J Glaucoma. 2010;19(5):324-330.

16. Nakazawa T, Nakazawa C, Matsubara A, et al. Tumor necrosis factoralpha mediates oligodendrocyte death and delayed retinal ganglion cell loss in a mouse model of glaucoma. $J$ Neurosci. 2006;26(49): 12633-12641.

17. Yuan L, Neufeld AH. Tumor necrosis factor-alpha: a potentially neurodestructive cytokine produced by glia in the human glaucomatous optic nerve head. Glia. 2000;32(1):42-50.

18. Kondkar AA, Azad TA, Almobarak FA, Kalantan H, Al-Obeidan SA, Abu-Amero KK. Elevated levels of plasma tumor necrosis factor alpha in patients with pseudoexfoliation glaucoma. Clin Ophthalmol. 2018; 12:153-159.

19. Takai Y, Tanito M, Ohira A. Multiplex cytokine analysis of aqueous humor in eyes with primary open-angle glaucoma, exfoliation glaucoma, and cataract. Invest Ophthalmol Vis Sci. 2012;53(1):241-247.

20. Ohira S, Inoue T, Iwao K, Takahashi E, Tanihara H. Factors influencing aqueous proinflammatory cytokines and growth factors in uveitic glaucoma. PLoS One. 2016;11(1):e0147080.

21. Ohira S, Inoue T, Shobayashi K, Iwao K, Fukushima M, Tanihara H. Simultaneous increase in multiple proinflammatory cytokines in the aqueous humor in neovascular glaucoma with and without intravitreal bevacizumab injection. Invest Ophthalmol Vis Sci. 2015;56(6):3541-3548.
22. Kuchtey J, Rezaei KA, Jaru-Ampornpan P, Sternberg P Jr, Kuchtey RW. Multiplex cytokine analysis reveals elevated concentration of interleukin-8 in glaucomatous aqueous humor. Invest Ophthalmol Vis Sci. 2010;51(12):6441-6447.

23. Chua J, Vania M, Cheung CM, et al. Expression profile of inflammatory cytokines in aqueous from glaucomatous eyes. Mol Vis. 2012; $18: 431-438$.

24. Borkenstein A, Faschinger C, Maier R, et al. Measurement of tumor necrosis factor-alpha, interleukin-6, Fas ligand, interleukin-1alpha, and interleukin-1 beta in the aqueous humor of patients with open angle glaucoma using multiplex bead analysis. Mol Vis. 2013;19:2306-2311.

25. Tong Y, Zhou YL, Zheng Y, Biswal M, Zhao PQ, Wang ZY. Analyzing cytokines as biomarkers to evaluate severity of glaucoma. Int $J$ Ophthalmol. 2017;10(6):925-930.

26. Bruunsgaard H, Pedersen BK. Age-related inflammatory cytokines and disease. Immunol Allergy Clin North Am. 2003;23(1):15-39.

27. Bozkurt B, Mesci L, Irkec M, et al. Association of tumour necrosis factor-alpha -308 G/A polymorphism with primary open-angle glaucoma. Clin Exp Ophthalmol. 2012;40(4):e156-e162.

28. Hamid MA, Moemen L, Labib H, Helmy H, Elsergany T. Risk of open angle glaucoma due to tumor necrosis factor alpha gene polymorphisms. Electron Physician. 2016;8(2):1978-1983.

29. Razeghinejad MR, Rahat F, Kamali-Sarvestani E. Association of TNFA -308 G/A and TNFRI $+36 \mathrm{~A} / \mathrm{G}$ gene polymorphisms with glaucoma. Ophthalmic Res. 2009;42(3):118-124.

30. Abu-Amero KK, Morales J, Bosley TM. Mitochondrial abnormalities in patients with primary open-angle glaucoma. Invest Ophthalmol Vis Sci. 2006;47(6):2533-2541.
Clinical Ophthalmology

\section{Publish your work in this journal}

Clinical Ophthalmology is an international, peer-reviewed journal covering all subspecialties within ophthalmology. Key topics include: Optometry; Visual science; Pharmacology and drug therapy in eye diseases; Basic Sciences; Primary and Secondary eye care; Patient Safety and Quality of Care Improvements. This journal is indexed on

\section{Dovepress}

PubMed Central and CAS, and is the official journal of The Society of Clinical Ophthalmology (SCO). The manuscript management system is completely online and includes a very quick and fair peer-review system, which is all easy to use. Visit http://www.dovepress.com/ testimonials.php to read real quotes from published authors. 